\title{
Optimizing Early Flowering and Pre-selection for Short Juvenile Period in Olive Seedlings
}

\author{
Inmaculada Moreno-Alías ${ }^{1}$ \\ IFAPA-Centro “Alameda del Obispo,” Avda. Menéndez Pidal s/n, 14004 \\ Córdoba, Spain; and Instituto de Agricultura Sostenible-C.S.I.C. Apdo. \\ 4084, 14080 Córdoba, Spain
}

\section{Hava F. Rapoport \\ Instituto de Agricultura Sostenible-C.S.I.C. Apdo. 4084, 14080 Córdoba, Spain}

\author{
Rafael López, Lorenzo León, and Raúl de la Rosa \\ IFAPA-Centro “Alameda del Obispo," Avda. Menéndez Pidal s/n, 14004 \\ Córdoba, Spain
}

Additional index words. Breeding, height, juvenility, Olea europaea, transplant time

\begin{abstract}
In recent years, the juvenile period of olive seedlings has been reduced by diverse forcing and pruning-formation techniques, but it is still a major drawback for breeding. Plant height at the time when seedlings are transplanted to the field has been found effective for obtaining earlier flowering, but the value of this parameter varies widely among olive breeding programs. We evaluated different transplant dates, taking into account mean plant height and age, with the aim of determining the optimum parameters for achieving early flowering and easy plant management and, at the same time, for the early elimination of genotypes with a long juvenile period. A mean seedling height of $\approx 100 \mathrm{~cm}$ at the time of planting in the field provided the best results in terms of shortening the juvenile period and facilitating handling of the seedlings. For all dates tested, seedling height at transplanting was effective as a pre-selection criterion for the early elimination of genotypes with long juvenile periods, with slight improvement in effectiveness with advancing transplant date.
\end{abstract}

The juvenile period, i.e., the time between seed germination and when the plant achieves and maintains the ability to flower, is very prolonged in woody species (Hackett, 1985). The length of this period is determined by genetic and environmental factors (Kazakov and Kichina, 1988), and their interaction can generate different plant behaviors. In the olive tree (Olea europaea, L.), the juvenile period can last up to 15 years in natural conditions (Bellini, 1993), and has represented one of the major obstacles for breeding programs in this crop species. Moreover, the length of the juvenile period has agronomic importance due to its relationship with the length of the unproductive period of the new cultivars subsequently reproduced by

Received for publication 19 Nov. 2009. Accepted for publication 2 Feb. 2010

This study was partly funded by Junta de Andalucía, Spain (grant no. AGR649) and by the European Social Fund. I.M.-A. is grateful to the IFAPA (Institute of Agricultural and Fishery Research and Training, Junta de Andalucía, Spain) for her research fellowship.

We thank Prof. Shimon Lavee and two anonymous reviewers for helpful suggestions regarding revision of the manuscript.

${ }^{1}$ To whom reprint requests should be addressed; e-mail inmaculada.moreno.a@gmail.com. vegetative cuttings, an important character for fruit trees. León et al. (2007) clearly demonstrated that olive seedlings with a short juvenile period will, once vegetatively propagated, also produce plants with a short unproductive period. Two main strategies have been used in fruit breeding programs to overcome these difficulties: 1) the development of early selection criteria to eliminate genotypes with a long juvenile period and 2) the shortening of this period by means of forced growth of seedlings.

Criteria for early selection of seedlings with a short juvenile period have been established for tree crop species such as apple (Alston and Bates, 1980; Visser et al., 1976; Zagaja and Faust, 1983), pear (Bagnara et al., 1994; Visser et al., 1976; Zimmerman, 1977) and, more recently, olive (De la Rosa et al., 2006; Pritsa et al., 2003; Rallo et al., 2008). In this latter species, early elimination of plants with a long juvenile period is based on plant height measured just before the time of transplanting to the field, excluding all seedlings shorter than a threshold height (De la Rosa et al., 2006; Rallo et al., 2008).

The second approach used to overcome the long juvenile period of fruit tree seedlings has been to force seedling growth, particularly to rapidly achieve height, in the greenhouse (Aldwinckle, 1975; Fischer, 1994) and/or field. In olive, the application of growth forcing and training has allowed a considerable reduction of the juvenile period, facilitating breeding program success (Lavee et al., 1996; Santos-Antunes et al., 2005). A number of growth-forcing strategies can be carried out. Santos-Antunes et al. (2005) forced growth in the greenhouse for 18 months and then planted the seedlings in the field with an average height of $160 \mathrm{~cm}$. This procedure, however, entails management difficulties such as a marked imbalance between a very tall shoot and a pot-restricted root volume before planting in the field and labor-intensive staking and pruning following transplant. On the contrary, Lavee et al. (1996) focused on forcing growth in the field, where seedlings were planted when they were only $30 \mathrm{~cm}$ high. Under field conditions, an adequate growth-forcing strategy is not limited by root volume, plant space, or other management considerations.

In this study, we evaluate the influence of olive seedling transplant date from three different perspectives: early attainment of the capacity to flower, simplification of plant management, and rapid elimination of less desirable genotypes. We integrate the two main strategies that have been used to overcome the juvenile period, simultaneously evaluating the effect of a range of heights at the time of transplant to the field on the percentage of plants with a short juvenile period and testing the applicability of the early selection criterion for juvenile period (De la Rosa et al., 2006) to different seedling ages. In particular, we attempt to define more precisely and optimize the transplant times that can be used successfully, using plant height, shown to be an effective parameter for both strategies, as our principal measurement.

\section{Materials and Methods}

Plant material. A total of 360 olive seedlings (coming from the olive breeding program of Córdoba, carried out by the University of Córdoba and IFAPA, Junta de Andalucía) originating from open pollination of 'Arbequina' were included in this study. Progenies of this origin have been shown to have a wide degree of variability in juvenile period length (De la Rosa et al., 2006). The full study was carried out over five-year period that included seed germination, seedling growth, and transplant to the field during the first year, and measurement of growth and flowering during the following four years. Seed germination was carried out in Dec. 2001 and seedling growth was forced in the greenhouse according to the procedure generally used in the Córdoba olive breeding program and reported by Santos-Antunes et al. (2005). During the greenhouse forcing phase, the seedlings were randomly divided into four groups of 90 plants each, corresponding to the four subsequent times for transplanting to the field.

Field trial transplant procedure. The growing seedlings were transplanted to the field at the IFAPA (Institute of Agricultural 
and Fishery Research and Training, Junta de Andalucía, Spain) experimental farm in Córdoba, Spain. The four groups were transplanted on four different dates, and thus had an increasing mean plant height at each subsequent transplant time, while maintaining a range of heights within the group due to genetic variability among the seedlings. The transplant dates were 22 May (G1), 23 June (G2), 25 July (G3), and 11 Sept. (G4) 2002, or $22,26,31$, and 38 weeks after germination, with average (final greenhouse) heights of 44 , 83, 109, and $135 \mathrm{~cm}$ for groups G1, G2, G3, and $\mathrm{G} 4$, respectively.

In the field, the plants were spaced at $1.5 \times$ $4 \mathrm{~m}$ and were trained to form the canopy at $160 \mathrm{~cm}$, above which they were allowed to develop freely. Drip irrigation and standard cultural practices were followed.

Trait evaluation. In the transplant year, each time a group was transplanted to the field, the height of all its plants, considered as the complete length of the main trunk, was measured, as was that of the previously transplanted and not yet transplanted groups. In the subsequent five years, it was measured during winter (Dec. 2002-06). The number of plants starting to flowering (interpreted as the beginning of the adult phase) was evaluated during the three first spring blooms (years 2004, 2005, and 2006).

Test of pre-selection. The data regarding seedling height at transplant and the final adult (flowering during the experimental period) or juvenile (not yet flowering) condition were used to perform a hypothetical elimination of the $25 \%$ shortest plants in each group to evaluate the potential removal (negative pre-selection) of undesirable genotypes with a long juvenile period at different times.

Data analysis. Data were subjected to analysis of variance to test the effect of the group transplant date on flowering. Height differences within each group at the time of planting in the field (greenhouse height) were evaluated in relation to the final juvenile or adult state of the plant.

\section{Results and Discussion}

Time of transplant influenced plant growth, indicated by height, and the length of the juvenile period later in field. As expected, plant growth was delayed by transplanting, although to a different extent for the different groups (Table 1). Only group G3, with an average height at planting of $109 \mathrm{~cm}$, continued its normal rhythm of growth after transplanting. During the first five seasons in the field, differences in height among groups gradually disappeared, except for the group G1 (mean height at transplant $44 \mathrm{~cm} / 22$ May), which consistently showed a mean height significantly lower than the rest of the groups (Table 2). The reported heights achieved at different times in the greenhouse are, in general, similar to those previously reported for olive seedlings (Adakalic et al., 2004). Height and age are indicators of plant growth status at transplant time, but many additional factors that were not included in this study, such as root development, will influence recovery and the resumption of growth.

A similar trend among groups was observed with regard to the juvenile-to-adult phase change, determined by the first year of flowering. In the first flowering year, two years after planting, all groups contained some flowering plants except G1 $(44 \mathrm{~cm} / 22$ May) (Fig. 1). In the following years, flowering plants were observed in all of the groups, but with G1 showing a lower percentage than the rest of groups. The lack of significant difference in flowering percentages among groups G2, G3, and G4 could be due to the high variation coefficient of the seedlings, similar to that noted by previous authors (Adakalic et al., 2004).

The results obtained indicate that earlier transplanting than described previously can facilitate olive seedling management while still maintaining a reduction of the juvenile period. The percentage of flowering plants obtained in groups G2, G3, and G4 is similar to that previously reported for olive seedlings, but seedling management was considerably simplified by shortening the greenhouseforcing period, transplanting smaller plants and reducing subsequent pruning. The $\mathrm{G} 2$ to G4 plants were on average 83 to $135 \mathrm{~cm}$ high, were transplanted 6 to 9 months after greenhouse forcing, and flowered for the first time three years after germination. Lavee et al. (1996) obtained $0 \%$ to $15 \%$ of flowering plants three years after germination and $0 \%$ to $78 \%$ in the next year, but needed to apply three to four heavy pruning treatments. Santos-Antunes et al. (2005) achieved 15\% flowering plants three years after germination and $51 \%$ of adult plants in the next year from seedlings transplanted to the field at $160 \mathrm{~cm}$ height and after 18 months of forced growth in the greenhouse. De la Rosa et al. (2006) and Rallo et al. (2008) used similar transplant

Table 1. Mean plant height $(\mathrm{cm})$ during the year of transplanting to the field. Height was recorded for all groups on all transplant dates. Each group was defined by a transplant mean height (values in the diagonal, in bold) and date (as week after germination). Values above the diagonal were recorded in the open field (after transplanting), whereas values below the diagonal were recorded in the greenhouse (before transplanting).

\begin{tabular}{llrrr}
\hline & \multicolumn{4}{c}{ Weeks after germination (Group transplanted) } \\
\cline { 2 - 5 } Group & $22(\mathrm{G} 1)$ & $26(\mathrm{G} 2)$ & $31(\mathrm{G} 3)$ & $38(\mathrm{G} 4)$ \\
\hline G1 & $\mathbf{4 3 , 7 2} \mathbf{a}^{\mathbf{z}}$ & $53,93 \mathrm{~b}$ & $59,41 \mathrm{~d}$ & $82,17 \mathrm{c}$ \\
$\mathrm{G} 2$ & $47,34 \mathrm{a}$ & $\mathbf{8 3 , 2 4} \mathbf{a}$ & $83,48 \mathrm{c}$ & $109,95 \mathrm{~b}$ \\
G3 & $50,75 \mathrm{a}$ & $87,5 \mathrm{a}$ & $\mathbf{1 0 8 , 9 4} \mathbf{a}$ & $130,73 \mathrm{a}$ \\
G4 & $45,59 \mathrm{a}$ & $80,08 \mathrm{a}$ & $99,58 \mathrm{~b}$ & $\mathbf{1 3 5 , 2 3} \mathbf{a}$ \\
\hline
\end{tabular}

${ }^{\mathrm{z}}$ Means with different letters within each column indicate significant differences $(P \leq 0.05)$.

Table 2. Mean plant height $(\mathrm{cm})$ of each group in December in five consecutive years (2002-06). G1 (transplant mean height of $44 \mathrm{~cm}), \mathrm{G} 2(83 \mathrm{~cm}), \mathrm{G} 3(109 \mathrm{~cm})$, and G4 $(135 \mathrm{~cm})$.

\begin{tabular}{lccccc}
\hline Group & 2002 & 2003 & 2004 & 2005 & 2006 \\
\hline G1 & $92,02 \mathrm{c}^{\mathrm{z}}$ & $193,25 \mathrm{~b}$ & $193,25 \mathrm{c}$ & $237,75 \mathrm{~b}$ & $263,86 \mathrm{~b}$ \\
G2 & $122,42 \mathrm{~b}$ & $215,44 \mathrm{a}$ & $244,87 \mathrm{ab}$ & $261,01 \mathrm{a}$ & $292,66 \mathrm{a}$ \\
G3 & $142,07 \mathrm{a}$ & $227,16 \mathrm{a}$ & $259,31 \mathrm{a}$ & $263,58 \mathrm{a}$ & $301,19 \mathrm{a}$ \\
G4 & $135,28 \mathrm{a}$ & $216,59 \mathrm{a}$ & $230,33 \mathrm{~b}$ & $261,29 \mathrm{a}$ & $297,00 \mathrm{a}$ \\
\hline
\end{tabular}

${ }^{\mathrm{z}}$ Means with different letter within each column indicate significant differences $(P \leq 0.05)$.

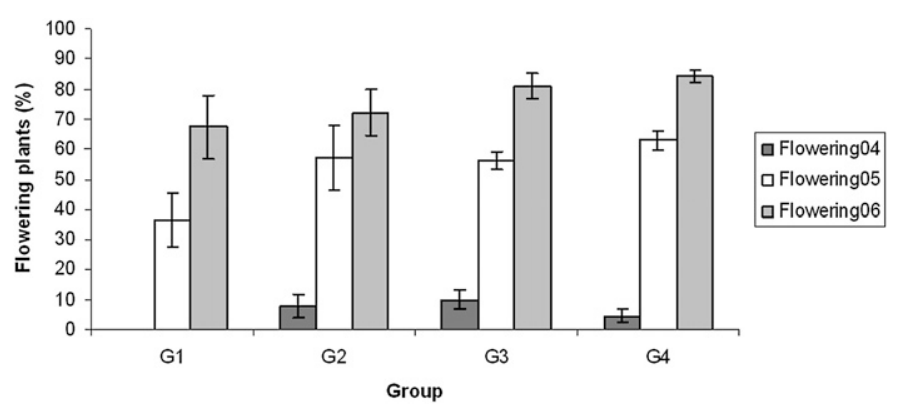

Fig. 1. Percentage of plants that flowered in the second, third, and fourth years $(2004,2005$, and 2006 , respectively) after planting for each group. G1 (transplant mean height of $44 \mathrm{~cm} / 22$ weeks after germination), G2 (83 cm/26 weeks), G3 (109 cm/31 weeks), and G4 (135 cm/38 weeks).

Table 3. Test of hypothetical seedling elimination: Relative flowering behavior of the $25 \%$ shortest seedlings in each group before transplant. For each transplant group, percentages represent the proportions of total "finally flowering" and total "not yet flowering" plants four years after transplanting to the field, which would have been eliminated in the $25 \%$ shortest seedlings before transplant. G1 (transplant mean height of $44 \mathrm{~cm} / 22$ weeks after germination), G2 (83 cm/26 weeks), G3 $(109 \mathrm{~cm} / 31$ weeks), and G4 (135 cm/38 weeks).

\begin{tabular}{lcccc}
\hline Group & G1 & G2 & G3 & G4 \\
\hline Not yet flowering & 37,50 & 46,43 & 52,17 & 63,16 \\
Flowering & 17,24 & 14,75 & 14,93 & 14,29 \\
\hline
\end{tabular}



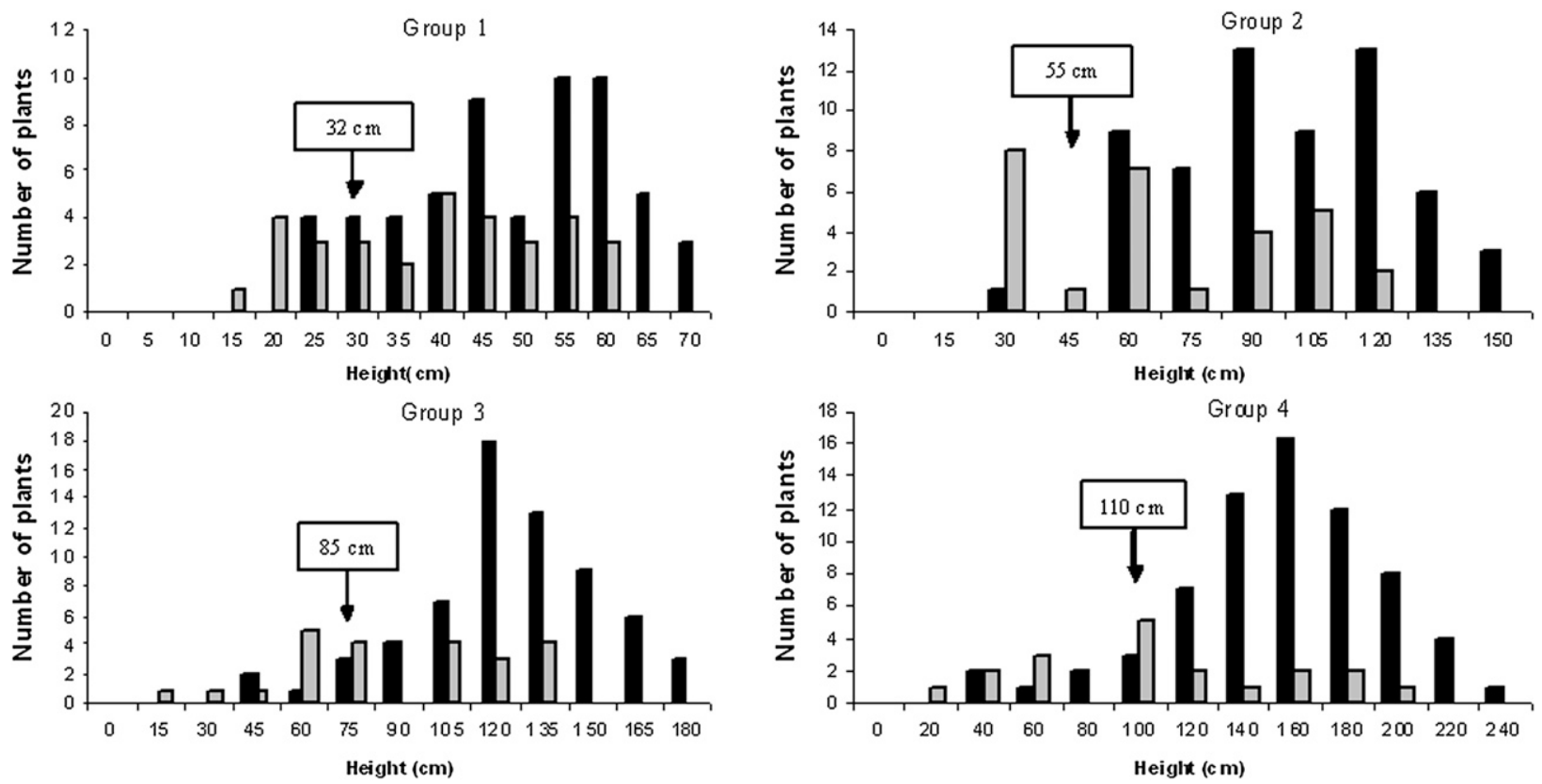

Fig. 2. Frequency distribution of plants for the greenhouse-to-field transplanting height according to finally flowering (grey) or still not (black) in the field four years after planting. The value in the box indicates the tested threshold height below which the $25 \%$ shortest seedlings would be eliminated. G1 (transplant mean height of $44 \mathrm{~cm} / 22$ weeks after germination), G2 ( $83 \mathrm{~cm} / 26$ weeks), G3 (109 cm/31 weeks), and G4 (135 cm/38 weeks). Ninety plants per group.

timing and heights as Santos-Antunes et al. (2005) and achieved similar flowering percentages, but Pritsa et al. (2003) required at least four years after germination to obtain substantial flowering in olive seedlings.

The results of the hypothetical seedling pre-selection strategy (Table 3; Fig. 2) indicated that elimination of the $25 \%$ shortest plants to remove undesirable genotypes with a long juvenile period can be effectively carried out at different times. For all four groups it was observed that the frequency distribution of seedlings by height at transplant time (greenhouse-to-field transplanting height) was strongly shifted to the taller plants for the finally flowering plants with respect to the still not flowering ones (Fig. 2). By rejecting the $25 \%$ of seedlings below the threshold height values, a much higher number of still not flowering (long juvenile period) than finally flowering (short juvenile period) seedlings would be eliminated from the initial progeny group (Table 3 ).

De la Rosa et al. (2006) proposed the early selection for olive tree juvenile period based on seedling height at the end of the greenhouseforcing period using a seedling-height threshold to exclude genotypes with a high likelihood of having a long juvenile phase. They suggested that the $25 \%$ to $33 \%$ shortest plants could be eliminated in the greenhouse, avoiding costly and time-consuming transplants to the field, because a high proportion of them would have a long juvenile period. This criterion was developed and initially tested for seedlings forced in the greenhouse for 18 months and averaging $160 \mathrm{~cm}$ at the time of planting in the field. Rallo et al. (2008) found that the elimination threshold was effective up to $40 \%$. In the current study setting, the early selection criterion threshold at eliminating the
$25 \%$ of plants with lowest height provided good results in all evaluated groups, although least of all in G1. In this group, the differences were less evident, thus the lowest percentage of long juvenile period plants would have been chosen for elimination as well as the highest percentage of short-juvenile-period plants (Table 3). For the rest of the groups (G2, G3, and G4), similar percentages of the long juvenile period plants $(50 \%)$, but only a small percentage of all the short juvenile period plants (around 15\%) would be eliminated, thus affirming the effectiveness of pre-selection for juvenile period based on seedling height.

The importance of height as an early plant characteristic in olive seedling growth is consistent with reports of seedling vigor, closely related to plant height, in other fruit trees species. In apple, Zagaja and Faust (1983) reported that low plant vigor observed in the first year of seedling growth was indicative of genotype. In pear, the first flowering seems to occur earlier in plant genotypes growing more vigorously during their first year (Costes et al., 2004).

In conclusion, the results of this study indicate that 26 to 31 weeks after germination, with a mean height of around $100 \mathrm{~cm}$, represents the ideal time for transplanting olive seedlings to the field under our conditions, providing more than $80 \%$ of adult plants four years later. Additionally, we have verified the pre-selection strategy of De la Rosa et al. (2006) based on seedling height at the time of planting and we have demonstrated its successful application to seedling groups of different ages and heights. Preselecting in this manner allows the elimination of more than $50 \%$ of the plants that would remain juvenile four or more years after planting and, at the same time, main- tains more than $85 \%$ of those flowering within four years after planting. These results represent a number of advantages for a breeding program, including improving the efficiency and results of the selection process, reducing the time for sexual generations, and lowering management costs for seedling maintenance in the greenhouse and transplanting operations.

\section{Literature Cited}

Adakalic, M., D. Barranco, L. León, and R. De la Rosa. 2004. Influence of harvest date on the germination and emergency of seeds of five olive cultivars. Fifth International Symposium on Olive Growing. Izmir, Turquía.

Aldwinckle, H.S. 1975. Flowering of apple seedlings 16-20 months after germination. HortScience 10:124-126.

Alston, F.H. and J.W. Bates. 1980. Selection for yield in apple progenies. France, INRA, Station d'Arboriculture Fruitiere, Angers, Proceedings of Eucarpia Fruit Section Symposium, Tree Fruit Breeding, Angers, 15-27.

Bagnara, G.L., M.L. Maltoni, M. Laghi, and L. Rivalta. 1994. Relationship between vegetative structure and early bearing in pear seedlings. Acta Hort. 367:101-108.

Bellini, E. 1993. Genetic variability and heritability of some characters in cross-bred olive seedlings. Olivae 49:21-34.

Costes, E., A. Belouin, L. Brouard, and M. Lelezec 2004. Development of young pear trees and occurrence of first flowering, a varietal comparison. J. Hort. Sci. Biotechnol. 79:67-74.

De la Rosa, R., A.I. Kiran, D. Barranco, and L. León. 2006. Seedling vigor as a preselection criterion for short juvenile period in olive breeding. Aust. J. Agr. Res. 57:477-481.

Fischer, C. 1994. Shortening of the juvenile period in apple breeding, p. 161-164. In: Schmidt, H., and M. Kellerhals (eds.). Progress in temperature fruit breeding. Kluwer Academic Publishers, Dordrecht, The Netherlands. 
Hackett, W.P. 1985. Juvenility, maturation, and rejuvenation in woody plants. Hort. Rev. (Amer. Soc. Hort. Sci.) 7:109-155.

Kazakov, I.V. and V. Kichina. 1988. Methods of accelerating the cropping of apple trees by reducing the juvenile phase. Acta Hort. 224:141-144.

Lavee, S., N. Avidan, A. Haskal, and A. Ogrodovich. 1996. Juvenility period reduction in olive seedlings: A tool for enhancement of breeding. Olivae 60:33-41.

León, L., R. De la Rosa, D. Barranco, and L. Rallo. 2007. Breeding for early bearing in olive. HortScience 42:499-502.
Pritsa, T.S., D.G. Voyiatzis, C. Voyiatzi, and M.S. Sotiriou. 2003. Evaluation of vegetative growth traits and their relation to time to first flowering of olive seedlings. Aust. J. Agr. Res. 54:371376.

Rallo, P., R. Jiménez, J. Ordovás, and M.P. Suárez. 2008. Possible early selection of short juvenile period olive plants based on seedling traits. Aust. J. Agr. Res. 59:933-940.

Santos-Antunes, F., L. León, R. De la Rosa, J. Alvarado, A. Mohedo, I. Trujillo, and L. Rallo. 2005. The length of the juvenile period in olive as influenced by vigor of the seedlings and the precocity of the parents. HortScience 40:12131215.

Visser, T., J.J. Verhaegh, and D.P. De Vries. 1976. A comparison of apple and pear seedlings with reference to the juvenile period. I. Seedling growth and yield. Euphytica 25:343-351.

Zagaja, S.W. and M. Faust. 1983. Population analysis of vigor and growth pattern of apple seedlings with short internode parentage. J. Amer. Soc. Hort. Sci. 108:939-944.

Zimmerman, R.H. 1977. Relation of pear seedling size to length of the juvenile period. J. Amer. Soc. Hort. Sci. 102:443-447. 